\title{
STUDIES OF THE COMPOSITION OF SECONDARY AMYLOID ${ }^{1}$
}

\author{
By ROBERT B. GILES, JR.2 AND EVAN CALKINS \\ (From the Department of Medicine, Harvard Medical School and the Medical Service of the \\ Massachusetts General Hospital, Boston, Mass.)
}

(Submitted for publication January 24, 1955; accepted May 18, 1955)

As part of a study of the pathogenesis of secondary amyloidosis it became apparent that more precise knowledge of the components of amyloid substance would be necessary to determine the sources from which these components come and the reasons for their appearance.

Although previous studies have indicated that amyloid substance is predominantly protein (1, $2)$, with a lesser amount of carbohydrate $(3,4)$, the exact amount and nature of the carbohydrate moiety has not been defined. One reason for this is that amyloid, because of its relative insolubility, is difficult to extract from tissues. Those extracts which have been obtained yielded material which may have been quite different from amyloid in the natural state. Furthermore, it is difficult to identify amyloid in a given fraction since its only identifying characteristics, its affinity for Congo-red, metachromasia, and site of deposition, - are no longer present.

The finding of an almost pure amyloid deposit at post mortem examination in a patient presented an excellent opportunity to determine the chemical composition of amyloid, unaltered by extraction procedures, and to obtain quantitative information on some of its components. In addition, similar studies were made on other tissues with and without amyloid to test the correlation between the concentrations of some of the components and the concentration of amyloid as estimated from histological examination.

\section{MATERIALS AND METHODS}

\section{Materials}

The relatively pure amyloid deposit was found in the liver of a 27-year-old white female dying of longstanding

\footnotetext{
1 This is publication No. 185 of the Robert W. Lovett Memorial for the Study of Crippling Diseases, Harvard Medical School, Boston, Massachusetts. Grants in support of these investigations have been received from the Commonwealth Fund, New York City, and from the Milton Fund of Harvard University.

2 Public Health Service Postdoctoral Research Fellow of the National Institute of Arthritis and Metabolic Diseases.
}

pulmonary tuberculosis and secondary amyloidosis of the liver, spleen, and kidneys. This lemon-sized tumorlike mass was firm and waxy in appearance and on histological examination appeared to consist almost entirely of amyloid substance. This substance exhibited the following histochemical staining properties: It stained slightly eosinophilic with hemotoxylin and eosin, exhibited metachromasia with methyl violet, had a strong affinity for Congo-red, a positive reaction with periodic acid-Schiff's reagent, and stained yellow with Verhoeff's elastic tissue stain with Van Giesen's counterstain. Schultz's stain for cholesterol, the Sudan III stain for fat, Baker's acid hematin stain for phospholipins and Feulgen's stain for desoxyribose nucleic acid were negative. Aside from the amyloid, some connective tissue and liver cell nuclei were seen. It was estimated that about 90 per cent of the tissue was amyloid substance.

The other tissues included in this study are listed in Table I, with their sources, and the approximate amount of amyloid present as judged from histological examination. All of the amyloid specimens represented secondary amyloid. The tissue labeled " $\mathrm{BC}$ " was the liver in which the amyloid deposit was found.

\section{Methods}

1. Water content: As soon as possible after obtaining the tissues, the water content was determined in duplicate by drying approximately $300 \mathrm{mgm}$. of tissue in vacuum over $\mathrm{P}_{2} \mathrm{O}_{5}$ at $110^{\circ} \mathrm{C}$. overnight. All tissues were then placed in sealed bottles and deep frozen and specimens for analysis were cut without thawing. The tissues used in chemical studies were dried in vacuum at $110^{\circ}$ C., and then pulverized. At the same time that portions of this powdered sample were removed for analysis, the water content of an aliquot was determined.

2. Nitrogen: Nitrogen determinations were done in quadruplicate by a micro Kjeldahl method using $\mathrm{CuSO}_{4}$ and selenium as catalysts. The digestion was carried out for six hours. Water blanks, standard $\left(\mathrm{NH}_{4}\right)_{2} \mathrm{SO}_{4}$ and a purified gelatin standard ${ }^{3}$ (nitrogen content of 18.3 per cent) were treated in the same fashion as the sample.

3. Hexosamine: The hexosamine content of the tissue was determined by the Boas modification of the Elson and Morgan reaction (5). The hexosamines and amino acids were separated from the neutral sugars and uronic acids by passing the acid hydrolysate of the tissue through a Dowex 50 ion exchange column. The neutral sugars and uronic acids, not being adsorbed by the resin, were obtained in the water wash; the hexosamines were adsorbed by the resin and finally eluted by $2 \mathrm{~N} \mathrm{HCl}$. The

\footnotetext{
3 Obtained from Dr. Jerome Gross.
} 
TABLE I

Analyses of liver tissues with and without amyloid from both humans and horses

\begin{tabular}{|c|c|c|c|c|c|c|}
\hline \multirow[b]{2}{*}{ Tissue } & \multirow[b]{2}{*}{ Primary disease } & \multirow[b]{2}{*}{$\begin{array}{l}\text { Estimated* } \\
\% \text { amyloid }\end{array}$} & \multirow[b]{2}{*}{$\% \mathrm{H}_{2} \mathrm{O}$} & \multicolumn{3}{|c|}{$\%$ of dry weight } \\
\hline & & & & $\begin{array}{l}\text { Neutral } \\
\text { sugart }\end{array}$ & Hexosamine & $\begin{array}{c}\text { Eronic } \\
\text { acid }\end{array}$ \\
\hline Amyloid deposit§ & Tuberculosis & 90 & 82.8 & 1.86 & 1.55 & $.60(2)$ \\
\hline $\begin{array}{l}\text { Human amyloid liver } \\
\mathrm{Zi}_{\mathrm{i}} \\
\text { Ad } \\
\mathrm{BC} \S\end{array}$ & $\begin{array}{l}\text { Rheumatoid arthritis } \\
\text { Rheumatoid arthritis } \\
\text { Tuberculosis }\end{array}$ & $\begin{array}{l}60 \\
50 \\
45\end{array}$ & $\begin{array}{l}76.2 \\
80.0 \\
77.1\end{array}$ & $\begin{array}{l}1.17(3) \\
1.57(3) \\
2.48(1)\end{array}$ & $\begin{array}{l}.60(8) \\
.96(4) \\
.62(2)\end{array}$ & $\begin{array}{l}.17(1) \\
.28(1)\end{array}$ \\
\hline $\begin{array}{l}\text { Human non-amyloid liver } \\
\text { We } \\
\mathrm{Fr}_{\mathrm{r}} \\
\mathrm{To} \\
\mathrm{Ta} \\
\mathrm{Gi} \\
\mathrm{Pe} \\
\mathrm{Hi}\end{array}$ & $\begin{array}{l}\text { Hypertension } \\
\text { Rheumatoid arthritis } \\
\text { Myocardial infarction } \\
\text { Cirrhosis of the liver } \\
\text { Sudden death (cause } \\
\text { undetermined) } \\
\text { Myocardial infarction } \\
\text { Carcinoma of ovary }\end{array}$ & $\begin{array}{l}0 \\
0 \\
0 \\
0 \\
0 \\
\\
0 \\
0\end{array}$ & $\begin{array}{l}74.0 \\
75.1 \\
64.3 \\
81.4 \\
74.1 \\
77.4 \\
64.9\end{array}$ & $\begin{array}{l}.92(2) \\
1.20(3) \\
2.8(1)\end{array}$ & $\begin{array}{l}.25(6) \\
.32(2) \\
.22(1) \\
.36(1) \\
.21(1) \\
.27(1) \\
.13(1)\end{array}$ & $.23(1)$ \\
\hline $\begin{array}{l}\text { Horse amyloid liver } \\
\mathrm{By} \\
\mathrm{Re} \\
\mathrm{Bx}\end{array}$ & $\begin{array}{l}\text { Tetanus immunization } \\
\text { Tetanus immunization } \\
\text { Tetanus immunization }\end{array}$ & $\begin{array}{l}40 \\
25 \\
20\end{array}$ & $\begin{array}{l}75.0 \\
69.0 \\
78.8\end{array}$ & $\begin{array}{r}5.8(1) \\
.75(2)\end{array}$ & $\begin{array}{l}.54(3) \\
.35(2) \\
.83(1)\end{array}$ & $\begin{array}{l}.45(1) \\
.15(2)\end{array}$ \\
\hline $\begin{array}{l}\text { Horse non-amyloid liver } \\
\text { Ka } \\
\text { Wh } \\
\text { Em } \\
\text { Le No. } 1 \\
\text { Le No. } 2\end{array}$ & $\begin{array}{l}\text { Normal horse } \\
\text { Tetanus immunization } \\
\text { Tetanus immunization } \\
\text { Botulinus immunization } \\
\text { Tetanus immunization }\end{array}$ & $\begin{array}{l}0 \\
0 \\
0 \\
0 \\
0\end{array}$ & $\begin{array}{l}69.5 \\
71.7 \\
70.7 \\
70.4 \\
73.9\end{array}$ & $\begin{array}{r}4.9(1) \\
6.0(1) \\
9.7(2) \\
5.1(2) \\
13.5(2)\end{array}$ & $\begin{array}{l}.19(1) \\
.25(1) \\
.28(2) \\
.35(2) \\
.35(2)\end{array}$ & $\begin{array}{l}.28(1) \\
.25(1) \\
.43(2) \\
.33(2) \\
.56(2)\end{array}$ \\
\hline
\end{tabular}

* The figures represent the mean of several observers' estimations of the amyloid concentrations of microscopic sections.

$\dagger$ Expressed as equal amounts of glucose and galactose.

$\ddagger$ The numbers in parentheses represent the number of determinations made for each mean value. The hexosamine values were determined from samples hydrolyzed for 2 to 16 hours, whereas the neutral sugar and uronic acid values were determined from samples hydrolyzed for 2 to 8 hours. In each case one 8-hour hydrolysis was performed, and when only one determination was made, the hydrolysis period was $\mathbf{8}$ hours. The values for the amyloid deposit, however, are the best values obtained with varying hydrolysis times (hydrolysis time for the hexosamine, 12 hours; for the neutral sugar, 2 hours; for the uronic acid, 2 hours). $2 \mathrm{~N} \mathrm{HCl}$ was used for hydrolysis in each case.

$\S$ The tissue " $\mathrm{BC}$ " is the liver in which the deposit was found.

hexosamine content was then measured by the Elson and Morgan reaction. Optimal hydrolysis conditions of the tissue with hydrochloric acid were established by varying both the normality of the acid and the time of hydrolysis (up to $6 \mathrm{~N}$ and 24 hours, respectively). Glucosamine hydrochloride and purified ovomucoid 4 (12 per cent glucosamine) were used as standards.

4. Neutral sugars: The neutral sugars obtained by the method outlined in the preceding paragraph were determined by the anthrone method of Loewus (6). As the color intensity of anthrone-sugar complexes varies with the sugar, the neutral sugar content must be expressed in terms of those sugars present in the sample. Inasmuch as the amyloid deposit contained approximately equal amounts of glucose and galactose, the per cent of neutral sugar of all the tissues in this study was calculated on this basis (as the non-amyloid tissues contained more glucose than galactose, the true values

* Obtained from the Worthington Chemical Corporation. for these tissues is slightly less than indicated). Optimal hydrolysis conditions with $\mathrm{HCl}$ were again determined by varying both normality and time of hydrolysis. This anthrone method was also applied directly to the dried, powdered, unhydrolyzed amyloid tissue (7). Glucose, galactose, mannose, and ovomucoid (10 per cent mannose) were used as standards.

5. Uronic acids: The uronic acid content of the water wash obtained above was determined by the napthoresorcinol method of Fishman, and his co-workers (8) recently modified as follows: To $3 \mathrm{cc}$. of the sample were added $2 \mathrm{cc}$. of .4 per cent naphthoresorcinol, and $2 \mathrm{cc}$. of $18 \mathrm{~N} \mathrm{H}_{2} \mathrm{SO}_{4}$. This was heated in an unstoppered test tube for one and one-half hours on a steam bath. The optical density of the toluene extracted pigment was read at $575 \mathrm{~m} \mu$. The optical hydrolysis conditions of the tissue with $\mathrm{HCl}$ were again determined by varying the normality and time of hydrolysis. The naphthoresorcinol method was applied as well to the dry, powdered, unhydrolyzed amyloid tissue. Glucuronolactone and galacturonic acid were used as standards. 
6. Amino acids and inorganic elements: Quantitative determinations of hydroxyproline (9), tyrosine (10), glycine (11), ash, total phosphorus ${ }^{5}$ and total sulfur, ${ }^{5}$ were made by standard methods.

7. Chromatography: The identification of the carbohydrate components was carried out by paper chromatographic methods. For the neutral sugar identification samples of approximately $50 \mathrm{mgm}$. were hydrolyzed with both $\mathrm{HCl}$ and $\mathrm{H}_{2} \mathrm{SO}_{4}$ in varying strengths and times. The optimal hydrolysis conditions were: hydrolysis with $4 \mathrm{~N}$ $\mathrm{HCl}$ for two hours at $100^{\circ} \mathrm{C}$., removal of the excess $\mathrm{HCl}$ with $\mathrm{AgCO}_{3}$, then passage of the filtrate through a Dowex 50 ion exchange column. The water wash was evaporated to dryness under nitrogen on a steam bath and dissolved in small amounts of 50 per cent ethanol in water for application to the paper. Three separate techniques and solvent systems were used: descending partition with butanol-ethanol-water $(4: 1: 1)$, for 44 hours, and multiple ascending development (12) with butanol-pyridinewater $(6: 4: 3)$, and with ethylacetate-acetic acid-water $(3: 1: 3)$. Both ammoniacal silver nitrate and analine phthalate were used to develop the chromatograms.

Preparation of the sample for hexosamine chromatography was identical with that for neutral sugars except that hydrolysis was longer (six hours) and the hexosamine was eluted from the resin column with $2 \mathrm{~N}$ $\mathrm{HCl}$. The sample was evaporated to dryness on a steam bath under nitrogen. The paper chromatographic procedure consisted of partition of the hexosamines in butanol-ethanol-water $(4: 1: 1)$, conversion of the hexosamines to their characteristic pentoses with ninhydrin, and then partition in a second dimension, as described by Stoffyn and Jeanloz (13). Some trailing of the hexosamines occurred during the first partition in this solvent system, but should not prove objectionable; for there are no known substances other than hexosamines which have a very low $R_{f}$ in this solvent system, that may be converted by ninhydrin into pentoses which have a relatively high $R_{f}$ in the same solvent system.

The relative amounts of the monosaccharides identified by these chromatograms were estimated directly with an A. H. Thomas Company Densigraph. Standard monosaccharides were prepared in the same fashion as the samples for identification of the unknowns and for densimetric comparison.

\section{RESULTS}

The water concentration of the amyloid deposit was 82.8 per cent. This figure corresponded with a water concentration of 77.1 per cent for the liver in which the specimen was found, suggesting a hydrophilic nature of this substance. Moreover, two of the three amyloid livers from horses exhibited water concentrations above the range of

5 The phosphorus and sulfur determinations were performed by Dr. Karl Ritter, Basel, Switzerland. values found for the non-amyloid horse livers. This same trend appeared in the water concentration of the amyloid livers from humans if compared with the value of 68 per cent for the water concentration of liver from normal humans (14). No suitable normal human controls were available for this study and so the values shown for the nonamyloid livers from patients dying from a variety of acute and chronic diseases were spread over a wide range.

The nitrogen concentration of the amyloid deposit was 14.20 per cent of its dry weight as compared with values of 12.10 per cent and 12.45 per cent for two non-amyloid livers from humans, "We" and "Fr," respectively. The nitrogen concentration of the amyloid liver, " $\mathrm{Zi}$," was 13.50 per cent.

The neutral sugar concentration of the amyloid deposit was 1.86 per cent of its dry weight after an optimum hydrolysis and separation on the resin column, and 2.21 per cent as determined on the unhydrolyzed liver tissue. These values are in rough agreement and are evidence that hydrolysis and recovery of the neutral sugars was adequate. Optimal hydrolysis of the amyloid deposit was found to occur with $2 \mathrm{~N} \mathrm{HCl}$ for two hours at $100^{\circ} \mathrm{C}$. Stronger acid or longer periods of hydrolysis caused considerable destruction of the sugars. All the other tissues were similarly hydrolyzed with $2 \mathrm{~N} \mathrm{HCl}$, although there was little difference in the yield for hydrolysis times between two and eight hours. Therefore, the neutral sugar values listed in Table I for the tissues other than the amyloid deposit, represent the means of all values with a hydrolysis time between two and eight hours. These values do not show significant differences between the amyloid and non-amyloid tissues. The high values for the nonamyloid horse livers probably reflect glycogen storage.

The hexosamine concentration of the amyloid deposit was 1.55 per cent of the dry weight. This optimum value was obtained after hydrolysis for 12 hours with $2 \mathrm{~N} \mathrm{HCl}$, although the yield with hydrolysis times at any interval between 2 and 16 hours did not differ significantly from this optimum value. The hexosamine values for the other tissues listed in Table I again demonstrate little difference when hydrolyzed for any interval between 2 and 16 hours, and therefore the 
values expressed in this table represent a mean of determinations within this range. Because others (5), however, have suggested that the optimal hydrolysis for hexosamines in liver tissue occurs at eight hours, at least one determination for each tissue was done at this time, and if only one hydrolysis was performed, it was for eight hours. As can be seen in Table I, the hexosamine concentration of amyloid containing livers was not only slightly higher than that of non-amyloid livers but also proportional to the amount of amyloid present. The range of values for the non-amyloid livers agreed well with that reported by others (5) for normal humans.

The uronic acid concentration of the deposit, obtained in maximum yield by hydrolyzing with $2 \mathrm{~N} \mathrm{HCl}$ for two hours, was .60 per cent. This value was in close agreement with the .57 per cent obtained by direct determination on the powdered unhydrolyzed amyloid tissue. There appears to be no significant difference between the values of the amyloid tissues and the non-amyloid tissues listed in Table I.

The total phosphorus concentration of the deposit was .03 per cent of dry weight ( $5.1 \mathrm{mgm}$. per cent of wet weight) as compared to .67 per cent (153 mgm. per cent wet weight) for the liver tissue " $B C$ " in which the deposit was found. The total phosphorus concentration of a non-amyloid liver "We" was .84 per cent (219 mgm. per cent wet weight). The total sulfur concentration of the deposit was .86 per cent of the dry weight. The ash content was 3.2 per cent of the dry weight.

Chromatographic studies of the neutral sugar fraction of the amyloid deposit hydrolysate showed that approximately equal amounts of glucose and galactose were present (see Figure 1) and accounted for the major portion of the neutral sugars. This finding was consistent with three different solvent systems. In addition reducing substances corresponding to mannose, fucose, and arabinose were detected in small quantities in those chromatograms developed with ethyl acetateacetic acid-water. Two other faint spots with low $R_{f}$ values and one with a high value were noted but could not be further identified.

Chromatographic identification of the hexosamine components of the amyloid deposit revealed that both glucosamine and galactosamine were

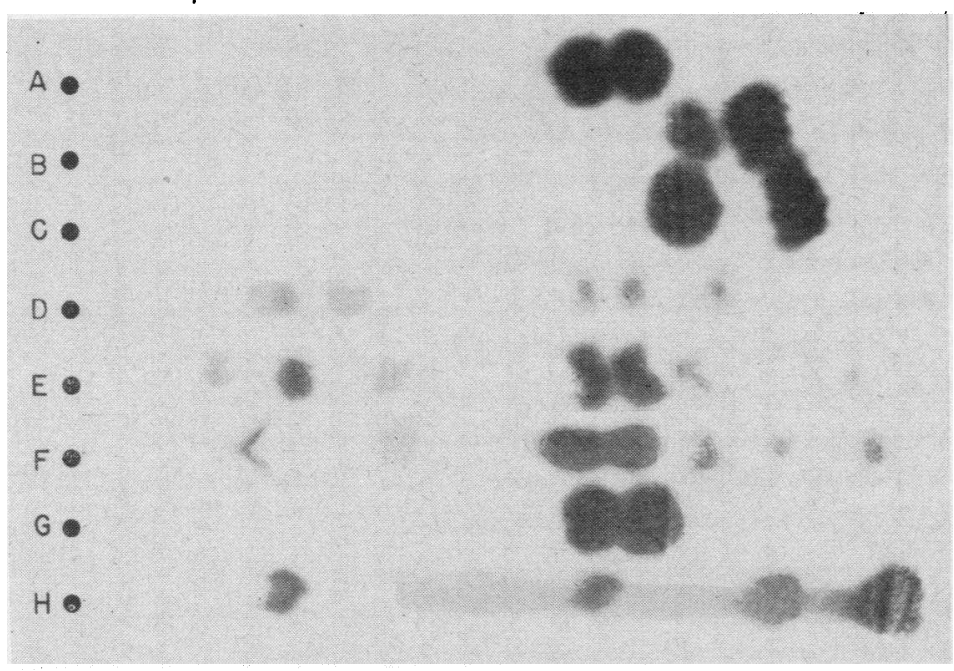

Fig. 1. Chromatogram for Neutral Sugars

Whatman No. 54 paper with 3 ascending developments, in butanol, pyridine and water $(6: 4: 3)$ stained with ammoniacal silver nitrate. The spots, reading from left to right are: A. Standard galactose, glucose; B. Standard mannose, fucose; C. Standard arabinose, ribose; D. Deposit hydrolysate ( 5 mgm., $2 \mathrm{~N} \mathrm{HCl}, 8$ hrs.) ; E. Deposit hydrolysate (20 mgm., $4 \mathrm{~N} \mathrm{HCl}, 6$ hrs.) ; F. Deposit hydrolysate (20 mgm., $4 \mathrm{~N} \mathrm{HCl}, 2$ hrs.) ; G. Standard galactose, glucose; $\mathrm{H}$. Standard glucuronic acid, galactose, $\mathrm{N}$-acetyl glucosamine, glucuronolactone. 


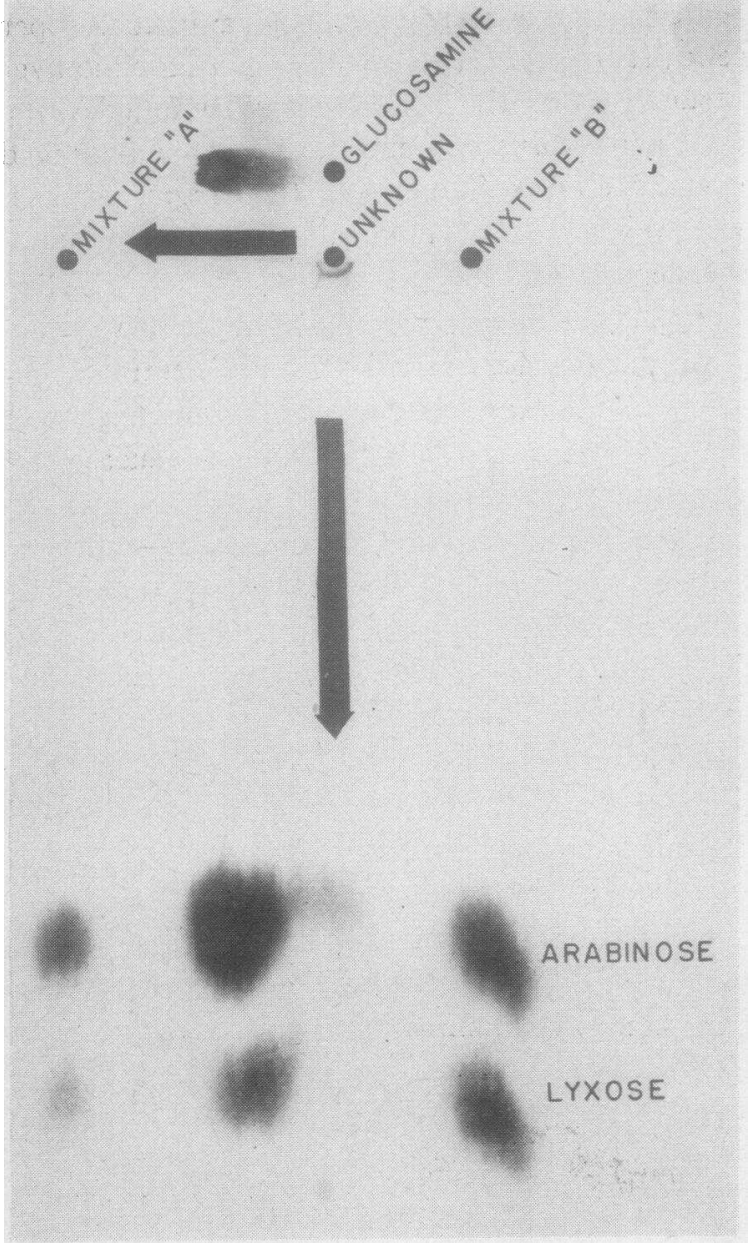

Fig. 2. Chromatogram for Aminosugars

The unknown $(20 \mathrm{mgm}$. of deposit hydrolyzed in $4 \mathrm{~N}$ $\mathrm{HCl}$ for 6 hours) and 100 gamma of glucosamine $\mathrm{HCl}$ developed 3 times (Top arrow) by an ascending method. After trimming off the reference spot (Top), mixture "A" (50 gamma of glucosamine $\mathrm{HCl}$ and 20 gamma of galactosamine $\mathrm{HCl}$ ) and mixture " $\mathrm{B}$ " (100 gamma of glucosamine and 100 gamma of galactosamine $\mathrm{HCl}$ ) were applied, the paper treated with ninhydrin and developed by a descending method (lower arrow) for 40 hours. Paper was Whatman No. 54 and solvents were butanol, ethanol, water $(4: 1: 1)$, stained with ammoniacal silver nitrate.

The lower spots on the figure are arabinose from glucosamine and lyxose from galactosamine.

present in a molecular ratio of approximately 4 to 1 (see Figure 2).

The concentrations of a few amino acids as determined by colorimetric methods were: hydroxyproline 1.5 per cent; glycine 3.8 per cent; and tyrosine 4.1 per cent. The low hydroxypro- line and glycine concentrations of this deposit indicate that collagen represented less than 10 per cent of the dry material.

\section{DISCLSSION}

Amyloid may be defined as a histologically homogeneous, amorphous material with characteristic sites of deposition and staining reactions. There yet remains a chemical analysis of the total tissue to establish whether this histologically homogeneous material is a single chemical complex, or whether it is a mixture of substances.

These data indicate that amyloid substance is protein combined with a small amount of carbohydrate. The histochemical characteristics of amyloid, i.e., the metachromasia and periodic acidSchiff reactivity, have long suggested that carbohydrates are present in the structure of amyloid. Nevertheless, the exact nature and amount of these carbohydrate components have been poorly defined. Krawkow (1) and later Hass (4) extracted from amyloid bearing organs small amounts of a substance which they believed to be similar to chondroitin sulfuric acid. Furthermore. Ehrström (3) noted that a mixture of chondroitin sulfuric acid and blood serum assumed a few of the staining properties of amyloid. On the other hand, Eppinger (2) comments on the absence of not only chondroitin sulfuric acid, but also carbohydrate in his preparation. Meyer (15), however, has identified glucosamine and a uronic acid in an extract of amyloid and felt that these constituted a heparin-like polysaccharide. Faber (16) has commented on the fact that more glucosamine was found in amyloid bearing liver than in a normal one, and Tolone and Pansini (17) have been able to produce amyloidosis in rabbits by the daily injection of glucosamine. Finally the name "amyloid" has unfortunately ingrained the impression that this substance is predominantly carbohydrate.

The results of this study indicate that carbohydrate could scarcely contribute more than 4 per cent of the solid material. Both glucosamine and galactosamine were identified chromatographically in the ratio of 4 to 1 , indicating that chondroitin sulfuric acid is not a major carbohydrate component. Furthermore, the hexosamine 
concentrations found in several amyloid containing livers from both human and horses were roughly proportional to the amyloid concentration as judged from histological examination. This serves to underscore the importance of this component in amyloid. Although other investigators have isolated from amyloid small amounts of polysaccharide, containing hexosamine, they have not accounted for as large an amount of hexosamine as observed in this study. Furthermore, the finding of bound neutral sugar in addition to the other carbohydrates indicates that amyloid substance, though homogeneous histologically, is probably a mixture of protein, glycoprotein and polysaccharide; for no carbohydrate complex has to our knowledge been isolated that contains the three carbohydrates-amino sugar, neutral sugar. and uronic acid.

The low total phosphorus concentration of the amyloid deposit was far below that found in the liver tissue surrounding the tumor, and was below that which would be expected were nucleic acid present in the same concentration in amyloid as in normal liver (normal human liver contains $85 \mathrm{mgm}$. of nucleo protein phosphorus per $100 \mathrm{gm}$. of wet weight, [18]). One would infer, therefore, that amyloid is probably not formed by mere coalescence of cytoplasmic and nuclear proteins of the liver into a homogeneous mass.

\section{SUMMARY}

The chemical composition of a relatively pure amyloid deposit obtained from the liver of a patient dying of tuberculosis and secondary amyloidosis has been studied.

1. Data are presented that indicate that it was predominantly a hydrophilic protein.

2. There were approximately 2 per cent of neutral sugars of which the main constituents were equal amounts of glucose and galactose.

3. The hexosamine concentration was 1.5 per cent. Both glucosamine and galactosamine were identified by chromatographic methods with the former predominating.

4. About .6 per cent of uronic acid was also found.

5. The total phosphorus concentration of this deposit was much less than that found in the surrounding liver tissue.
6. Observations of other human and horse livers both with and without amyloid, suggest that the hexosamine concentration and amyloid concentration were related.

\section{ACKNOWLEDGMENT}

The authors are indebted to Dr. Walter Bauer for his encouragement and suggestions throughout the course of this study, to Dr. A. Baird Hastings for his help in the preparation of this manuscript, to Dr. Roger W. Jeanloz and Dr. Jerome Gross for aid in the performance of some of these analyses, and especially to Dr. Dante Compagno Pinto, Department of Pathology, Boston City Hospital, from whom the amyloid deposit was obtained. The horse tissues were supplied by the Massachusetts Department of Public Health, the State of New York Department of Health, the Lederle Laboratories Division, and the Wyeth Laboratories, Inc., and are gratefully acknowledged.

\section{REFERENCES}

1. Krawkow, N. P., Beiträge zur Chemie der Amyloidentartung. Arch. f. exper. Path. u. Pharmakol., 1897, 40, 196.

2. Eppinger, H., Zur Chemie der Amyloiden Entartung. Biochem. Ztschr., 1922, 127, 107.

3. Ehrström, M. Ch., Chondroitinschwefelsäuren, Heparin, Albuminurie, Amyloid und Serumproteine. Acta med. Scandinav., 1939, 101, 551.

4. Hass, G., Studies of amyloid II. The isolation of a polysaccharide from amyloid-bearing tissues. Arch. Path., 1942, 34, 92.

5. Boas, N. F., Method for the determination of hexosamines in tissues. J. Biol. Chem., 1953, 204, 553.

6. Loewus, F. A., Improvement in anthrone method for determination of carbohydrates. Anal. Chem., 1952, 24, 219.

7. Bangle, R., Jr., and Alford, W. C., The chemical basis of the periodic acid Schiff reaction of collagen fibers with reference to periodate consumption by collagen and by insulin. J. Histochem. \& Cytochem., 1954, 2, 62.

8. Fishman, W. H., Smith, M., Thompson, D. B., Bonner, C. D., Kasdon, S. C., and Homburger, F., Investigation of glucuronic acid metabolism in human subjects. J. Clin. Invest., 1951, 30, 685.

9. Martin, C. J., and Axelrod, A. E., A modified method for determination of hydroxyproline. Proc. Soc. Exper. Biol. \& Med., 1953, 83, 461.

10. Block, R. J., and Bolling, D., The Amino Acid Composition of Proteins and Food; Analytical Methods and Results. Springfield, Charles C Thomas, 1951, p. 113.

11. Christensen, H. N., Riggs, T. R., and Ray, N. E., Glycine determination in tissues. Anal. Chem., 1951, 23, 1521. 
12. Jeanes, A., Wise, C. S., and Dimler, R. J., Improved techniques in paper chromatography of carbohydrates. Anal. Chem., 1951, 23, 415.

13. Stoffyn, P. J., and Jeanloz, R. W., Identification of amino sugars by paper chromatography. Arch. Biochem. \& Biophys., 1954, 52, 373.

14. Shohl, A. T., Mineral Metabolism. New York, Reinhold Publishing Corp., 1939, p. 15.

15. Meyer, K., The biological significance of hyaluronic acid and hyaluronidase. Physiol. Rev., 1947, 27, 335 .
16. Faber, M., The serum glucosamine with particular regard to its significance in connection with the origin of amyloid deposits. Acta med. Scandinav., 1948, 130, 351, Suppl. 206.

17. Tolone, S., and Pansini, H., Nuovo metodo di produzione dell'amiloidosi speriomutule. Boll. Soc., ital. biol. sper., 1949, 25, 1008.

18. Davidson, J. N., and Waymouth, C., Nucleic acids and tissue growth. Nutrition Abstr. \& Rev., 1944, 14, 1. 